\title{
New Insights Regarding Rationale, Therapeutic Target and Dose of Hemofiltration and Hybrid Therapies in Septic Acute Kidney Injury
}

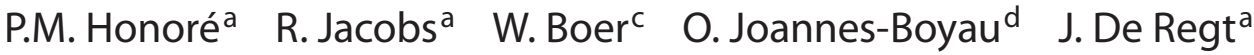 \\ E. De Waele ${ }^{a} \quad$ V. Van Gorp ${ }^{a} \quad$ V. Collin ${ }^{b} \quad$ H.D. Spapen ${ }^{a}$
}

a Intensive Care Department, Universitair Ziekenhuis Brussel, Vrije Universiteit Brussel, and b Intensive Care Unit, Cliniques de I'Europe-Site St Michel, Brussels, and 'Department of Anesthesiology and Critical Care Medicine, Ziekenhuis Oost-Limburg, Genk, Belgium; ${ }^{\mathrm{d}}$ Haut Leveque University Hospital of Bordeaux, University of Bordeaux 2, Pessac, France

\section{Key Words}

Hemofiltration - Sepsis - Septic shock - Systemic inflammatory response syndrome $\cdot$ Kidney injury, acute $\cdot$ Tubular apoptosis, acute $\cdot$ Sepsis modulation - Dialysis • Continuous renal replacement therapy

\begin{abstract}
Mediator removal from tissue (capillary blood compartment, $C A B C$ ) and transport to the central circulation (central blood compartment, CEBC) must be effective. Effectiveness through a passive mechanism seems unlikely as the surface of CEBC $\left(30 \mathrm{~m}^{2}\right)$ is smaller than CABC $\left(300 \mathrm{~m}^{2}\right)$ whereby the former will be a limiting factor in passive transport. According to studies, a high exchange volume can induce an 80fold increase in lymphatic flow. This results in displacement (active transport) of mediators to CEBC. Recent studies have shown that the delivered dose constitutes the mainstay of continuous renal replacement therapy. However, these results are not likely to change the recommendation: $35 \mathrm{ml} /$ $\mathrm{kg} / \mathrm{h}$, adjusted for predilution, in septic acute kidney injury (AKI). Recently, studies were focusing on global intensive care unit AKI. In non-septic AKI, those studies show that 20 $25 \mathrm{ml} / \mathrm{kg} / \mathrm{h}$ was optimal. The DO-RE-Ml trial underscored the importance of delivery which could be obtained by target-
\end{abstract}

ing doses between 5 and $10 \mathrm{ml} / \mathrm{kg} / \mathrm{h}$ higher than prescribed. Until the IVOIRE trial becomes available, septic AKI should be treated by continuous veno-venous hemofiltration at $35 \mathrm{ml} /$ $\mathrm{kg} / \mathrm{h}$. In non-septic AKI, $25 \mathrm{ml} / \mathrm{kg} / \mathrm{h}$ remains optimal.

Copyright $\odot 2011$ S. Karger AG, Basel

\section{Introduction}

Despite considerable progress in blood purification therapies over the years, numerous questions remain. Consequently, uncertainty persists among clinicians about the mode and dose of hemofiltration therapy to be used in patients with septic shock complicated by acute kidney injury (AKI) [1,2]. Septic shock remains a leading cause of mortality in intensive care patients [3]. Moreover, mortality in sepsis-induced AKI is significantly higher than in non-septic AKI [4-6]. While several milestone studies in the last decade $[7,8]$ have shown that the dose of therapy was of paramount importance regarding mortality, more recent trials have challenged this concept $[9,10]$. It stands to reason that a critical minimum dose is still desirable and that below this defined dose, mortality will be affected $[11,12]$. Furthermore, it seems theoretically reasonable to assume that effective removal of me-

\section{KARGER}

Fax +41613061234 E-Mail karger@karger.ch www.karger.com
(C) 2011 S. Karger AG, Base

0253-5068/12/0333-0044\$38.00/0

Accessible online at:

www.karger.com/bpu
Patrick M. Honoré, MD

Director of Critical Care Nephrology Platform, Intensive Care Department

Universitair Ziekenhuis Brussel, Vrije Universiteit Brussel

BE-1090 Brussels (Jette) (Belgium)

Tel. +32 24749 097, E-Mail Patrick.Honore@ uzbrussel.be 
diators from the tissue, where they are harmful, and transporting them to the central circulation must have a positive effect. Effectiveness through a mere passive transportation mechanism seems unlikely because the surface area of the central blood compartment (CEBC; $\pm 30 \mathrm{~m}^{2}$ ) is much smaller than that of the capillary blood compartment $\left(\mathrm{CABC} ; \pm 300 \mathrm{~m}^{2}\right)$ [13] whereby the former will be the limiting factor in passive transport. When a given passive technique is able to remove $40 \%$ of the mediators from the CEBC, this will represent only $4 \%$ removal from the CABC [14-18]. It is therefore likely that another active transportation mechanism will come into play [13]. We will review the most recent insights regarding the rationale and mechanisms of the 'new active transportation between two asymmetric compartments' hypothesis [13]. We will also analyze the strengths and the weaknesses of the so-called recent negative studies regarding the dose of continuous renal replacement therapy (CRRT) in critically ill patients.

\section{New Active Transportation between Two Asymmetric Compartments: Hypothesis and New Insights into Rationale and Potential Mechanisms}

Following clearance from the blood compartment, both pro-mediators and mediators are removed at interstitial and tissue levels until a so-called threshold point is reached at which some pathways and cascades are stopped $[19,20]$. At this level, the interrupted cascades cease to harm the tissues. Until recently, this mechanism was thought to be entirely passive. As alluded to in the introduction, an explanation for effectiveness based only on a passive transportation mechanism is unsatisfactory. The potential benefit of high-volume hemofiltration (HVHF) and especially high-replacement volumes (3-5 liters/h) in septic shock has repeatedly been emphasized $[13,15]$. It was thought, yet insufficiently understood, that the increased removal of middle and large molecules by HVHF enhanced immunomodulation during septic shock [19, $20]$. However, it was only recently demonstrated that the high-replacement volumes used during hemofiltration could not only remove but also displace mediators throughout the body $[16,21]$. As demonstrated in several studies, this technique can induce an up to 20 - to 80 -fold increase in lymphatic flow $[16-19,21]$. This can result in a concomitant substantial drag and displacement of mediators and cytokines to the blood compartment where they become available for removal. Thus, the use of high volumes of replacement fluid might not only account for actual extraction but also for stimulation of lymphatic transport between the interstitium, tissue compartments and blood, although these are known to be asymmetric. Once the mediators enter the lymphatic system, they become available for removal both at the CEBC side and by the liver and the reticuloendothelial system. The latter act as a buffer absorbing huge quantities of mediators during a storm and releasing them in the aftermath to make them available for removal by hemofiltration at a later stage $[22,23]$. Obviously, confirmation of this new working hypothesis would necessitate several experiments which are underway - incorporating the latest technology regarding nuclear imaging technique for effective tracing of mediators during their journey from the tissues through the lymphatic circulation into the CEBC [22]. Another more invasive procedure would be the catheterization of the thoracic duct to collect lymphatic fluid for direct measurement of mediator levels as was previously performed in severe acute pancreatitis [24]. A feasible alternative might be the measurement of indirect variables of reduced activity of tissue mediators such as markers of apoptosis and oxidative stress, in particular in inflammatory cells [25]. In septic rats, Kellum et al. [26] studied the effect of hemofiltration on liver production of mediators through nuclear factor (NF)- $\kappa \mathrm{B}$ production. Application of hemofiltration improved not only hemodynamics but also survival. This experiment also highlighted that hemofiltration not only reduced mediator blood levels but also hepatic mediator production. The exact mechanism of this upstream downregulating effect remains to be elucidated. Nevertheless, measurement of NF- $\mathrm{KB}$ production might also be considered as an indirect tool to estimate the reduction of pro-mediator production induced by hemofiltration-related immunomodulation. An in vivo implementation of this technique, however, would require systematic liver biopsy which is a too invasive procedure in critically ill patients.

\section{New Therapeutic Target Defined within the Latest Findings}

A recently published study by Kellum et al. [27] on cytokine levels in sepsis and septic shock (the so-called Genetic and Inflammatory Markers of Sepsis (GenIMS) Study) shows results that could challenge the timing of initiation of hemofiltration. This study in nearly 2,000 patients hospitalized for community-acquired pneumonia [27] evaluated the pro- and anti-inflammatory balance by measuring the ratio of interleukin-6 (IL-6/Pro-) 
over interleukin-10 (IL-10/Anti-). Subsequent analysis was performed to determine if a defined profile of this ratio predicted evolution of community-acquired pneumonia to sepsis, septic shock and eventually death. Of all included patients, $31 \%$ developed severe sepsis and $26 \%$ exhibited high circulating levels of cytokines. The highest risk of death was found to be correlated with a high ratio of pro- and anti-inflammatory levels of cytokines $(p<0.001)$. Based on these findings, a hemofiltration technique lowering the levels of pro- and anti-inflammatory cytokines and thus modulating the cytokine profile so that immune homeostasis is restored, could conceivably improve survival. Initiation of hemofiltration would then prove beneficial regardless of the phase (either hyper-inflammation or immuno-paralysis) of the septic process [28], although delay could still be detrimental [11, 22].

\section{Recent Positive Studies Regarding Blood Purification for AKI in ICU Patients}

A landmark study on dosing of blood purification in the intensive care unit (ICU) was published by Ronco et al. [7]. This prospective randomized controlled study including 425 ICU patients with AKI compared 3 doses of therapy: 20, 35 and $45 \mathrm{ml} / \mathrm{kg} / \mathrm{h}$. Survival in the 35 - and $45-\mathrm{ml} / \mathrm{kg} / \mathrm{h}$ group was significantly higher than in the $20-\mathrm{ml} / \mathrm{kg} / \mathrm{h}$ group with a difference of nearly $20 \%$ and $\mathrm{p}$ values of 0.0007 and 0.0013 , respectively. Furthermore, survivors in the $35-$ and $45-\mathrm{ml} / \mathrm{kg} / \mathrm{h}$ groups had a significantly lower baseline urea than non-survivors, suggesting that timing determined study outcome $[7,29]$. This study also set the standard for use of a high-volume technique in septic patients since increasing the volume of treatment from 35 to $45 \mathrm{ml} / \mathrm{kg} / \mathrm{h}$ improved outcome in this subgroup, suggesting that septic AKI should be handled differently $[7,28,29]$. In general, hemofiltration was put forward as a viable therapeutic intervention in the ICU. The volume of treatment could not only be tailored for body weight but also for severity and type of illness (e.g. septic vs. non-septic AKI). Finally, the authors studied renal recovery and indeed the percentage of complete renal recovery was 95,92 and $90 \%$, respectively, suggesting that dosing might determine an ultimate improvement in kidney function. The findings of this pivotal study were confirmed by Saudan et al. [8]. In a prospective randomized study, these authors compared 2 groups of ICU patients with AKI treated either with continuous veno-venous hemofiltration $(\mathrm{CVVH})$ alone at a dose of $25 \mathrm{ml} / \mathrm{kg} / \mathrm{h}$ or with continuous veno-venous hemodiafil- tration (CVVHDF) at a dose of $25 \mathrm{ml} / \mathrm{kg} / \mathrm{h}$ in CVVH plus a supplemental dose of CVVHDF of $18 \mathrm{ml} / \mathrm{kg} / \mathrm{h}$, giving a total dose of $42 \mathrm{ml} / \mathrm{kg} / \mathrm{h}$, which is comparable to the 35 $\mathrm{ml} / \mathrm{kg} / \mathrm{h}$ dose in the Ronco study [7]. The 28-day survival rate was $39 \%$ in the $25-\mathrm{ml} / \mathrm{kg} / \mathrm{h}$ group and $59 \%$ in the 42 $\mathrm{ml} / \mathrm{kg} / \mathrm{h}$ group $(\mathrm{p}<0.03)$. Renal recovery was 71 and $78 \%$, respectively, again suggesting that a higher dose was correlated with more renal improvement. Similarly, a prospective randomized study by Schiffl et al. [30] comparing extended daily dialysis (EDD) with every-other-day 4-hour dialysis (EOD) in ICU patients with AKI found a mortality rate at the end of dialysis treatment of $28 \%$ in the EDD and $46 \%$ in the EOD group. Kidney function normalized also much faster in the EDD group suggesting that dosing, regardless of the technique used, significantly affected renal recovery [31]. As mentioned earlier, a number of observational studies [32-34] using higher fluid replacement in $\mathrm{CVVH}$ seems to demonstrate an additional beneficial effect of this strategy on survival, although methodological shortcomings must be considered. Recently, a South American group headed by Cornejo et al. [35] performed a similar observational study using protocol-directed HVHF $(85 \mathrm{ml} / \mathrm{kg} / \mathrm{h}$ for $6-$ $8 \mathrm{~h}$ ) in 20 septic patients with multiple organ dysfunction syndrome and obtained comparable results. They created an algorithm based on international guidelines for sepsis treatment and incorporated intermittent HVHF $(100 \mathrm{ml} /$ $\mathrm{kg} / \mathrm{h}$ for a single 12 -hour period) as a salvage therapy for patients with refractory septic shock [35]. Despite being single-centered, non-randomized, and uncontrolled, these studies all produced similar results proving at least that HVHF can be delivered safely. Consequently, they stated that in hemodynamically unstable patients with AKI in need of therapy, CRRT should be preferred.

\section{Update on Recent Negative Trials in AKI in Critically III Patients}

Since the previous studies were promising, the results of larger randomized controlled clinical trials on dosing and timing of renal replacement therapy (RRT) were eagerly awaited. The VA/NIH study compared 2 different doses of CRRT ( 20 vs. $35 \mathrm{ml} / \mathrm{kg} / \mathrm{h}$ ) as well as 2 different intensities of intermittent RRT, depending on the hemodynamic status of the patient [9]. The study failed to demonstrate that intensive renal support in critically ill patients with AKI decreased mortality, enhanced recovery of kidney function, or reduced the rate of non-renal organ failure as compared to less intensive therapy. However, 
the study was criticized [11, 12], notably concerning the supposed $35-\mathrm{ml} / \mathrm{kg} / \mathrm{h}$ dose of CVVH in the intensive treatment group. This group was split into a $18-\mathrm{ml} / \mathrm{kg} / \mathrm{h}$ dialysis dose $(1,500 \mathrm{ml} / \mathrm{h})$ and a $17-\mathrm{ml} / \mathrm{kg} / \mathrm{h}$ convection dose, accounting for an actual dose of roughly $15 \mathrm{ml} / \mathrm{kg} / \mathrm{h}$ (when considering the pre-dilution instead of full postdilution modality). Additionally, the patients were enrolled and treated relatively late during their course of illness as compared to other studies (after a mean of 7 days in the ICU and 10 days in hospital). It is also worth noting that more than $65 \%$ of the patients received either intermittent hemodialysis or sustained low-efficiency dialysis treatment within $24 \mathrm{~h}$ prior to randomization. A Swedish study, definitely more suited to address timing in RRT, demonstrated the importance of the initial therapy on the renal recovery rate following AKI in ICU patients [36]. In the same vein, a recent review highlighted that the delay in timing in the VA/NIH (ATN) trial [9], most probably accounted for the high rate of dialysis dependency [37]. A study in 12 French ICUs evaluated the impact of early hemofiltration [38] on organ dysfunction, plasma cytokines and mortality. The study was designed and initiated in the late 1990s before the publication of the Ronco data [7] which explains why the dose of hemofiltration was fixed ( 2 liters/h) and not adapted to body weight. Of the 80 patients enrolled, 76 entered the study protocol. Patients with severe sepsis or septic shock without any form of kidney dysfunction were included to receive hemofiltration within the first $24 \mathrm{~h}$ following initial organ failure. The included septic patients did not suffer any form of acute kidney dysfunction when hemofiltration was initiated. Randomization was performed between either hemofiltration on top of standard sepsis treatment or standard sepsis treatment alone. As body weight approached $80 \mathrm{~kg}$, the final dose was approximately $25 \mathrm{ml} / \mathrm{kg} / \mathrm{h}$, thus largely below the $35 \mathrm{ml} / \mathrm{kg} / \mathrm{h}$ given in the Ronco study [7]. The primary objective was to evaluate the number, severity and duration of organ failures on day 14 using the Sepsis (Related) Organ Failure Assessment (SOFA) score. The study was ended prematurely due to insufficient inclusion but also because the number and severity of organ failures was significantly higher in the hemofiltration as compared to the control group. Nevertheless, mortality between groups was not significantly different at any time despite a trend in favor of the control group. In conclusion, initiation of hemofiltration (at least with a dose of $25 \mathrm{ml} / \mathrm{kg} / \mathrm{h}$ ) in 'classic' hyperdynamic septic shock without AKI did not offer any survival benefit unless septic shock becomes refractory. Whether the same applies for a dose of $35 \mathrm{ml} / \mathrm{kg} / \mathrm{h}$ re- mains to be answered. In the recent Randomized Evaluation of Normal versus Augmented Level (RENAL) study [10], 1,508 critically ill patients with AKI were randomized to receive a CVVHDF dose of either 25 or $40 \mathrm{ml} /$ $\mathrm{kg} / \mathrm{h}$. No difference in 90 -day mortality, the primary endpoint of the study, was observed between the two groups. Although randomized and extremely well conducted by leading experts in the field, a few criticisms can be made. First, $50 \%$ of the dose was applied in diffusion, reducing the convection dose to only $20 \mathrm{ml} / \mathrm{kg} / \mathrm{h}$ in the higher intensity group, which is significantly below the $35 \mathrm{ml} / \mathrm{kg} / \mathrm{h}$ used in the Ronco study [7]. Second, the study was designed to study global AKI. Both septic and non-septic AKI patients were studied, thus precluding dose evaluation in 'pure' septic or septic shock patients with AKI [39]. Interestingly, the almost exclusive use of CRRT in combination with the early timing in this trial reduced the rate of dialysis dependency by $50 \%$ when compared to the NIH study $[9,40]$. Based on the findings of the RENAL trial, it can be stated that a dose of $25 \mathrm{ml} / \mathrm{kg} / \mathrm{h}$ might be sufficient for treatment of non-septic AKI.

\section{Potential Impact of High Cut-Off Membranes in Future Sepsis Trials}

A number of years ago, a pilot trial studied the performance of high cut-off membranes in septic patients with AKI [41]. Thirty patients were randomized to treatment with either a high cut-off membrane (HCO) $( \pm 60 \mathrm{kD})$ or with a classic cut-off membrane $( \pm 35 \mathrm{kD})$. In the HCO group, a significant reduction in noradrenaline dose $(\mathrm{p}<$ $0.0002)$ and a tenfold increase $(\mathrm{p}<0.0001)$ in clearance of IL- 6 and IL-Ra was observed as compared to the classic membrane group.

The preliminary results of the recently completed High Cut-Off Sepsis study (HICOSS) were presented at the 10th World Federation of Societies of Intensive and Critical Care Meeting in Florence [42]. This study randomized 120 patients with septic shock and AKI to either a conventional membrane or an HCO membrane (cut-off of $60 \mathrm{kD}$ ). Patients were treated for 5 consecutive days in CVVHD mode. The study was stopped prematurely after enrolment of only 81 patients due to a lack of difference in 28 -day mortality (31\% for the HCO group and 33\% for the conventional group). No difference was seen in vasopressor need, duration of mechanical ventilation, or duration of ICU stay. No difference in albumin levels was found between the 2 groups, suggesting that the $\mathrm{HCO}$ membrane is safe for clinical use. It should be emphasized 
that the study was performed using CVVHD, thus precluding the observation of synergy between HVHF and high-permeability hemofiltration (HPHF). The CVVH mode, however, seems to be efficient for removal of mediators and cytokines. Indeed, in an ex vivo study [43], blood from healthy volunteers was spiked with endotoxin and then exposed to a 100-kD HCO filter at a dose of 16.6 $\mathrm{ml} / \mathrm{kg} / \mathrm{h}$ or to the same filter at a dose of $80 \mathrm{ml} / \mathrm{kg} / \mathrm{h}$. Clearance of cytokines was nearly 10 -fold higher (statistically significant) in the mixed HCO and HVHF group demonstrating synergy between HVHF and HPHF [43].

The future of HCO membranes in sepsis, in spite of the recent negative study (HICOSS), could still be of interest as potential synergies could be founded by mixing HVHF and HPHF together and also by combining HCO with highly adsorptive membranes.

Therefore, studies should go on with combinations of techniques. Very recent reports have been encouraging especially in non-traumatic and traumatic rhabdomyolysis in ICU patients [44].

\section{What Could Be the Future in Blood Purification?}

Before entering those considerations, we have to spend some time on definitions regarding $\mathrm{HVHF}$ and, according to several groups of experts including ours [45], continuous high-volume treatment with $50-70 \mathrm{ml} / \mathrm{kg} / \mathrm{h} 24 \mathrm{~h} /$ day and intermittent HVHF with brief, very-high-volume treatment at $100-120 \mathrm{ml} / \mathrm{kg} / \mathrm{h}$ for a short period of $4-8 \mathrm{~h}$, followed by conventional CVVH [45]. This latter strategy is also called 'pulse HVHF' and this concept was initially developed by Brendolan et al. [46]. This definition is also consistent with the proceedings of the 2001 Melbourne Critical Care Nephrology Conference where HVHF was defined as ultrafiltration flow rates of $>50 \mathrm{ml} / \mathrm{kg} / \mathrm{h}$ and very high HVHF for ultrafiltration flow rates of $>100 \mathrm{ml} /$ $\mathrm{kg} / \mathrm{h}$ [47]. This initial consensus definition of HVHF was called latter by some experts as 'The Pardubice' definition of HVHF in reference to the initial working party [45]. In the early 2000s, it was also decided to universally use milliliter per kilogram per hour as the unit to express the ultrafiltration flow rate [47]. However, for other experts, the use of slightly lower ultrafiltration rates was already considered as HVHF. Indeed, the Acute Dialysis Quality Initiative workgroup defines HVHF as $>35 \mathrm{ml} / \mathrm{kg} / \mathrm{h}$ [48]. The definition was then referred to by some experts as the New York definition of HVHF. We would like to state that in 2011, we are sticking on the pulse-HVHF definition of the Melbourne Pardubice approach with runs of 100-120 ml/ $\mathrm{kg} / \mathrm{h}$ for a period of $4-8 \mathrm{~h}$. Regarding continuous HVHF, we are now more in line with the so-called New York approach with a dose of $>35 \mathrm{ml} / \mathrm{kg} / \mathrm{h}$. While many large randomized trials investigating hemofiltration dose in AKI patients have been completed, one remains that compares HVHF with standard CVVH in septic AKI. The IVOIRE study (hIgh VOlume in Intensive caRE) aims to compare treatment with CVVH at 35 versus $70 \mathrm{ml} / \mathrm{kg} / \mathrm{h}$ in septic AKI for a period of $96 \mathrm{~h}$ [49-51]. The 96-hour period was based on the findings of the PROWESS study. As early treatment initiation was shown to be associated with improved survival, it was decided to start therapy at the RIFLE classification injury level [52]. Though the first patient was randomized by the end of November 2005, most centers joined in mid 2006. The overall primary objective of this study was to assess the effect of early high-volume CVVH $(70 \mathrm{ml} / \mathrm{kg} / \mathrm{h})$ on the 28 -day mortality rate in patients with septic shock complicated by acute renal insufficiency. Secondary objectives included evaluation of the effect of hemofiltration on morbidity, hemodynamic parameters, dose and duration of catecholamine treatment, resolution of organ failure, duration of mechanical ventilation and ICU stay, extravascular lung water volume, and mortality at 96 h, 60 and 90 days. The IVOIRE study was a randomized multicenter clinical trial designed as a superiority trial, aiming to detect a reduction of at least $15 \%$ in mortality rate. A sample size of 240 patients in each arm was calculated to obtain $>80 \%$ power to detect such effect at an $\alpha$ of 0.5 . Patients were treated in accordance with current evidence-based guidelines.

The coordinating team of the IVOIRE trial conducted two preliminary pilot studies $[53,54]$. The choice of hemofiltration volume in the control group $(35 \mathrm{ml} / \mathrm{kg} / \mathrm{h}$ ) was motivated by the latest literature recommendations applied to intensive care in the early 2000s. As no data exist favoring a specific treatment volume, the choice for the high-volume group $(70 \mathrm{ml} / \mathrm{kg} / \mathrm{h})$ was made by consensus, based on both intensive care practices using the latest techniques and round tables with experts in the field. The duration of treatment ( $96 \mathrm{~h}$ ) was motivated by the experience of the team and pilot studies which were conducted over similar time intervals. Duration corresponds with the critical period of septic shock when treatment is thought to have the highest impact on survival and is conform with the duration of sepsis treatments in current studies. Block randomization was used through access of a dedicated website. Data on loss of trace elements, vitamins, amino acids and other nutrients, and also on apoptosis, oxidative stress, renal repair capacity index, cytokines and mediators, and antibiotic pharmacokinetics are 
being collected as part of this study. By the end of December 2009, more than 140 patients had been randomized with more than 45 subjects enrolled in the last 12 months. The statistical analysis was initially perform and completed between the two groups but had to be reevaluated as one group was significantly sicker than the other and thus a new analysis is still in progress. The expected mortality of the actually enrolled patients according to three severity scoring systems (SOFA, SAPS II and LOD) was $68 \%$, whereas the observed mortality at 28 days was $39 \%$ and at 90 days only 51\%. This observed global mortality is much lower than expected and proves that the HVHF technique is safe and that early initiation (at injury level) may improve survival. Future analysis will learn whether a $>70-\mathrm{ml} / \mathrm{kg} / \mathrm{h}$ dose is beneficial in septic shock complicated by AKI plus three organ failures. More details on the study can be found on the NCT website [49]. Other recent studies must be mentioned. The EUPHAS (Early Use of Polymyxin B Hemoperfusion in Abdominal Sepsis) study investigated the impact of polymyxin B hemoperfusion (PMX) on hemodynamics, SOFA score and mortality in 64 patients with abdominal sepsis requiring urgent laparotomy [55]. The patients were randomized into a PMX or a control group. After adjustment for differences in initial SOFA scores, the group treated with PMX showed significant improvement in hemodynamics and mortality at 28 days. This selected group of patients exhibited no signs of renal injury. The study received several criticisms because of the low number of patients, the early termination and also the power of the study itself $[56,57]$. Therefore, two large randomized studies have been launched on the same topic but with different study schemes in the USA and France. The DO-RE-MI study (Dose Response Multicenter International Collaborative Initiative) incorporated over 30 ICUs in 8 countries [58]. This study was observational, cross-sectional and uncontrolled. Its primary objective was to study the effect of CRRT dose. Of 15,200 ICU patients, 553 had AKI and were treated with CRRT or intermittent renal replacement therapy. No difference was found in mortality between the $<35-\mathrm{ml} / \mathrm{kg} / \mathrm{h}$ group versus the $>35-\mathrm{ml} / \mathrm{kg} / \mathrm{h}$ group. Patients receiving a dose of $>35 \mathrm{ml} / \mathrm{kg} / \mathrm{h}$ also had a shorter duration of mechanical ventilation and ICU length of stay. An important finding of this study was that the delivered dose was significantly lower than the prescribed dose. The difference amounted to approximately $8 \mathrm{ml} / \mathrm{kg} / \mathrm{h}$ suggesting prescription of about $5-10 \mathrm{ml}$ more than the targeted dose. Major future challenges for blood purification will be the exact timing of initiation during AKI $[59,60]$ as well as a better delineation of the type of
AKI $[61,62]$. Very recently, attention has also been focused on potential side effects due to the undesired loss of vital substances which could eventually be circumvented by the recently described hybrid techniques, such as coupled plasma filtration and adsorption (CPFA) and cascade hemofiltration (CCHF). Only target molecules within a relatively strict range of molecular weights are adsorbed and treated blood is returned to the patient. Indeed, CPFA improves blood pressure and restores immune function in patients with severe sepsis and multi-organ dysfunction but failed so far to improve survival in large randomized studies [63]. Regarding CCHF in an animal model of septic shock, CCHF was superior to HVHF regarding hemodynamics. We do have data regarding mortality. Implementation at the bedside might be complicated and labor-intensive [64]. Although randomized and controlled with a positive significant impact on survival, the study of Busund et al. [65] was criticized due to the relatively low number of patients, its being monocentric and perhaps underpowered [66]. Two other large randomized trials were also negative [66]. Finally, there are recent reports regarding high adsorptive membranes, such as the study by Rimmelé et al. [67], especially with a combined system of membranes, that are able to run with a CRRT system but also able to eliminate endotoxin. Indeed, in their animal model, they were able to show a better hemodynamic improvement as compared to classic CRRT. Indeed, a full scale of new-generation membranes has emerged that focuses on endotoxin adsorption (Toraymyxin $^{\circledR}$, Toray $^{\mathrm{TM}}$ or Oxiris $\left.{ }^{\circledR}, \mathrm{Gambro}^{\mathrm{TM}}\right)$ or specific immuno-adsorption (Prosorba ${ }^{\circledR}$, Fresenius ${ }^{\mathrm{TM}}$ ). Preliminary results are promising [67], and future large randomized controlled trials are being prepared [68]. Other promising experimental approaches with combined hybrid techniques are currently being investigated after interesting initial report regarding rescue therapy [69].

\section{Conclusions and Recommendations for the ICU Clinician at the Bedside}

Effective removal of mediators from the tissue, where they are harmful, and transporting them to the central circulation must have a positive effect. Effectiveness through a mere passive transportation mechanism seems unlikely because the surface area of the CEBC $\left( \pm 30 \mathrm{~m}^{2}\right)$ is much smaller than that of the CABC $\left( \pm 300 \mathrm{~m}^{2}\right)$ whereby the former will be the limiting factor in passive transport. It is therefore likely that another active transportation mechanism will come into play. 
As demonstrated in septic animals and humans, a high volume of exchange (3-5 liters) can induce an up to 20- to 80 -fold increase in lymphatic flow. This can result in a concomitant substantial drag and displacement of mediators and cytokines to the blood compartment where they become available for removal. Optimization of the delivered dose definitely has a role to play. Actually, an ultrafiltration rate of around $35 \mathrm{ml} / \mathrm{kg} / \mathrm{h}$, with adjustment for predilution, should be recommended for the septic patient with AKI. The VA/NIH has too many limitations to have the power to change this recommendation and the RENAL study was not designed to specifically assess the septic AKI population. Nevertheless, both together are giving a strong signal that a target dose of $20-25 \mathrm{ml} / \mathrm{kg} / \mathrm{h}$ is associated with the best survival. Nevertheless, the message has to be refined as such for clinicians at the bedside. A continuous technique, preferably a pure CVVH mode, is recommended in septic AKI and even more in septic shock patients with AKI. The DO-RE-MI study has shown that the effective delivered dose is of crucial importance and targeting a prescribed dose of 5-10 $\mathrm{ml}$ higher than the calculated dose is a prerequisite. As demonstrated in the RENAL study, $25 \mathrm{ml} / \mathrm{kg} / \mathrm{h}$ should be the target dose in non-septic AKI. Again, the caveats learnt from the DORE-MI study imply that the targeted dose should be above the calculated one. Preliminary results from the IVOIRE study demonstrate that HVHF is safe and that early intervention at the injury level of kidney dysfunction may be warranted. Further analysis will reveal whether a dose of $>35 \mathrm{ml} / \mathrm{kg} / \mathrm{h}$ is beneficial in septic shock complicated by AKI and three other organ failures. Of note, the RENAL study has shown that the use of a continuous technique will dramatically reduce the risk of end-stage kidney injury with dialysis dependency.

\section{References}

1 Rimmelé T, Kellum J: Clinical review: blood purification for sepsis. Crit Care 2011;15: 205.

-2 Bellomo R, Palevsky PM, Bagshaw SM, Gibney N, Honore PM, Joannes-Boyau O, Prowle J, Cruz D, Ronco C: Recent trials in critical care nephrology. Contrib Nephrol 2010;165: 299-309.

-3 Vincent J-L, Atalan HK: Epidemiology of severe sepsis in the intensive care unit. $\mathrm{Br} \mathrm{J}$ Hosp Med 2008;69:442-443.

$\checkmark 4$ Parmar A, Langenberg C, Wan L, May CN, Bellomo R, Bagshaw SM: Epidemiology of septic acute kidney injury. Curr Drug Targets 2009;10:1169-1178.

5 Joannes-Boyau O, Honoré PM, Boer W, Rose T: Septic acute kidney injury and inflammatory apoptosis: never a lone ranger. Intensive Care Med 2010;36:385-388.

$\checkmark 6$ Silva S, de Cal M, Cruz D, et al: Oxidative stress and 'monocyte reprogramming' in septic patients with acute kidney injury requiring CRRT. Blood Purif 2008;26:188-92.

$\checkmark 7$ Ronco C, Bellomo R, Homel P, et al: Effect of different doses in continuous veno-venous haemofiltration on outcomes of acute renal failure: a prospective randomised trial. Lancet 2000;356:26-30.

$\checkmark 8$ Saudan P, Niederberger M, de Seigneux S, et al: Adding a dialysis dose to continuous hemofiltration increases survival in patients with acute renal failure. Kidney Int 2006;70: 1312-1317.

>9 Palewsky PM, Zhang JH, O’Connor TZ, et al: Intensity of renal support in critically ill patients with acute kidney injury. N Engl J Med 2008;359:7-20.
10 Bellomo R, Cass A, Cole L, et al: Intensity of continuous renal-replacement therapy in critically ill patients. N Engl J Med 2009;361: 1627-1638.

11 Ronco C, Cruz D, Oudemans van Straaten HM, Honore PM, House AA, Gibney N: Dialysis dose in acute kidney injury: no time for therapeutic nihilism - a critical appraisal of the Acute Renal Failure Trial Network study. Crit Care 2008;12:308.

12 Ronco C, Honore PM: Renal support in critically ill patients with acute kidney injury (letter). N Engl J Med 2008;359:1959-1962.

13 Honoré PM, Joannes-Boyau O, Jacobs R Solignac M: Blood purification in sepsis: fiction or fact for the clinician. Reanimation 2010;19:7-12.

14 van Deuren M, van der Meer JW: Hemofiltration in septic patients is not able to alter the plasma concentration of cytokines therapeutically. Intensive Care Med 2000;26: 1176-1178.

15 Honoré PM, Zydney AL, Matson JR: High volume and high permeability haemofiltration in sepsis. The evidences and the key issues. Care Crit Ill 2003;3:69-76.

16 Olszewski WL: The lymphatic system in body homeostasis: physiological conditions. Lymph Fat Res Biol 2003;1:11-21.

17 Onarherim H, Missavage E, Gunther RA, Kramer GC, Reed RK, Laurent TC: Marked increase of plasma hyaluronan after major thermal injury and infusion therapy. J Surg Res 1991;50:259-265.

18 Wasserman K, Mayerson HS: Dynamics of lymph and plasma protein and exchange. Cardiologia 1952;21:296-307.
19 Ronco C, Bellomo R: Acute renal failure and multiple organ dysfunction in the ICU: from renal replacement therapy (RRT) to multiple organ support therapy (MOST). Int J Artif Organs 2002;733-747.

20 Matson JR, Zydney AR, Honore PM: Blood filtration: new opportunities and the implications on system biology. Crit Care Resuc 2004;6:209-218.

-21 Di Carlo JV, Alexander SR: Hemofiltration for cytokine-driven illness: the mediator delivery hypothesis. Int J Artif Organs 2005;28: 777-786.

$>22$ Honore PM, Joannes-Boyau O, Boer W, Collin V: High-volume hemofiltration in sepsis and SIRS: current concepts and future prospects. Blood Purif 2009;28:1-11.

23 Honoré PM, Joannes-Boyau O: High volume hemofiltration (HVHF) in sepsis: a comprehensive review of rationale, clinical applicability, potential indications and recommendations for future research. Int J Artif Organs 2004;27:1077-1082.

24 Dugernier T, Reynaert MS, Deby-Dupont G, et al: Prospective evaluation of thoracic-duct drainage in the treatment of respiratory failure complicating severe acute pancreatitis. Intensive Care Med 1989;15:372-378.

\25 Mariano F, Cantaluppi V, Stella M, et al: Circulating plasma factors induce tubular and glomerular alterations in septic burn patients. Crit Care 2008;12:R42.

26 Kellum JA, Song M, Venkataraman R: Hemoadsorption removes tumor necrosis factor, interleukin-6, and interleukin-10, reduces nuclear factor-kappaB DNA binding, and improves short-term survival in lethal endotoxemia. Crit Care Med 2004;32:801-805. 
27 Kellum JA, Kong L, Fink MP, et al, for the GenIMS Investigators: Understanding the inflammatory cytokine response in pneumonia and sepsis: results of the Genetic and Inflammatory Markers of Sepsis (GenIMS) Study. Arch Intern Med 2007;167:1655-1663.

28 Honore PM, Joannes-Boyau O, Boer W, Collin V, Jennes S: Continuous haemofiltration in 2009: what's new for clinicians regarding pathophysiology, preferred technique and recommended dose? Blood Purif 2009;28: 135-143.

-29 Ronco C, Ricci Z, Bellomo R: Importance of increased ultrafiltration volume and impact on mortality: sepsis and cytokine story and the role for CVVH. EDTNA ERCA J 2002(suppl 2):13-18.

-30 Schiffl H, Lang SM, Fisher R: Daily hemodialysis and the outcome of acute renal failure. N Engl J Med 2002;346:305-310.

- 31 Honore PM, Joannes-Boyau O, Collin V, Boer W, Gressens B, Janvier G: Practical daily management of extra-renal continuous removal. Reanimation 2008; 17:472-478.

- 32 Cole L, Bellomo R, Journois D, Davenport P, Baldwin I, Tipping P: High-volume haemofiltration in human septic shock. Intensive Care Med 2001;27:978-986.

33 Ratanarat R, Brendolan A, Piccinni P, et al: Pulse-high volume haemofiltration for treatment of severe sepsis: effects on hemodynamics and survival. Crit Care 2005;9:294-302.

34 Piccinni P, Dan M, Barbacini S, et al: Early isovolaemic haemofiltration in oliguric patients with septic shock. Intensive Care Med 2006;32:80-86.

35 Cornejo R, Downey P, Castro R, et al: Highvolume hemofiltration as salvage therapy in severe hyperdynamic septic shock. Intensive Care Med 2006;32:713-722.

- 36 Bell M, SWING, Granath F, Schon S, Ekbom A, Martling CR: Continuous renal replacement therapy is associated with less chronic renal failure than intermittent haemodialysis after acute renal failure. Intensive Care Med 2007:33:773-780.

-37 Ridel C, Balde MC, Rondeau E, Vinsonneau $\mathrm{C}$ : Dose of dialysis in intensive care unit. Reanimation 2009;18:385-396.

38 Payen D, Mateo J, Cavaillon JM, Fraisse F, Floriot C, Vicaut E, Hemofiltration and Sepsis Group of the Collège National de Réanimation et de Médecine d'Urgence des Hôpitaux extra-Universitaires: Impact of continuous veno-venous hemofiltration on organ failure during the early phase of severe sepsis: a randomized controlled trial. Crit Care Med 2009;37:803-810.

39 Joannes-Boyau O, Honoré PM, Boer W, Collin V: Are the synergistic effects of high-volume haemofiltration and enhanced adsorption the missing key in sepsis modulation? Nephrol Dial transplant 2009;24:354-357.

40 Prowle JR, Bellomo R: Continuous renal replacement therapy: recent advances and future research. Nat Rev Nephrol 2010;6:521529.
41 Morgera S, Haase M, Kuss T, et al: Pilot study on the effects of high cut-off hemofiltration on the need for norepinephrine in septic patients with acute renal failure. Crit Care Med 2006;34:2099-2104.

42 Honore PM, Clark W: Preliminary results of the HICOSS study. Proc 10th WFSCICCM, Florence, Italy, 2009.

43 Uchino S, Bellomo R, Goldsmith D, et al: Super high flux hemofiltration: a new technique for cytokine removal. Intensive Care Med 2002;28:651-655.

44 Stollwerck PL, Namdar T, Stang FH, Lange T, Mailänder P, Siemers F: Rhabdomyolysis and acute renal failure in severely burned patients. Burns 2011;37:240-248.

45 Honore PM, Joannes-Boyau O, Kotulak T: Report of the working party on high volume hemofiltration including definitions and classification. Proc 2nd Czech Conference on Critical Care Nephrology, Pardubice, Czech Republic, 2007.

-46 Brendolan A, D'Intini V, Ricci Z, et al: Pulse high volume hemofiltration. Int J Artif Organs 2004;27:398-403.

47 Honore PM, Jamez J, Wauthier M: Very high volume hemofiltration: a comprehensive review. Int Symp Critical Care Nephrology, Melbourne, 2001.

48 Kellum JA, Mehta RL, Angus DC, Palevsky $\mathrm{P}$, Ronco C: The first international consensus conference on continuous renal replacement therapy. Kidney Int 2002;62:1855-1863.

49 Joannes-Boyau O, Honore PM: Hemofiltration study: IVOIRE Study: clinicaltrials.gov ID NCT00241228 (accessed April 2011).

50 Joannes-Boyau O, Honore PM: Preliminary data of the IVOIRE study. Proc 19th Int Vicenza Course of CRRT, Vicenza, Italy, 2010.

-51 Bellomo R, Palevsky PM, Bagshaw SM, Gibney N, McAlister FA, Honore PM, et al: Recent trials in critical care nephrology; in Ronco C, Bellomo R, McCulloufgh PA (eds): Cardiorenal Syndromes in Critical Care. Contrib Nephrol. Basel, Karger, 2010, vol 165, pp 299-309.

52 Bellomo R, Ronco C, Kellum J, Mehta R, Palevsky P, ADQI Workgroup: Acute renal failure - definition, outcome measures, animal models, fluid therapy and information technology needs: the Second International Consensus Conference of the Acute Dialysis Quality Initiative (ADQI) Group. Crit Care 2004;8:R204-R212.

53 Honoré PM, Jamez J, Wauthier M, et al: Prospective evaluation of short term high volume isovolemic hemofiltration on the hemodynamic course and outcome in patients with intractable circulatory failure resulting from septic shock. Crit Care Med 2000;28: 3581-3587.

54 Joannes-Boyau O, Rapaport S, Bazin R, Fleureau C, Janvier G: Impact of high volume hemofiltration on hemodynamic disturbance and outcome during septic shock. ASAIO J 2004;50:102-109.
55 Cruz DN, Antonelli M, Fumagalli R, et al: Early use of polymyxin $\mathrm{B}$ hemoperfusion in abdominal septic shock: the EUPHAS randomized controlled trial. JAMA 2009;301: 2445-2452.

56 Kellum JA, Uchino S: International differences in the treatment of sepsis: are they justified ? JAMA 2009;301:2496-2497.

57 Vincent JL: Polymyxin B hemoperfusion and mortality in abdominal septic shock. JAMA 2009;302:1968-1969.

-58 Vesconi R, Cruz DN, Fumagalli R, et al: Delivered dose of renal replacement therapy and mortality in critically ill patients with acute kidney injury. Crit Care 2009;13;R57.

-59 Honore PM, Joannes-Boyau O, Boer W, Rose T: Real-time non-invasive follow-up of acidbase correction by the kidney: a step closer. Minerva Anestesiol 2010;76:307-309.

60 Jacobs R, Honore PM, Joannes-Boyau O, et al: Septic acute kidney injury: the culprit is inflammatory apoptosis rather than ischemic necrosis. Blood Purif 2011;32:262-265.

61 Honore PM, Jacobs R, Boer W, JoannesBoyau O: Sepsis and AKI: more complex than just a simple question of chicken and egg. Intensive Care Med 2011;37:186-189.

62 Honore PM, Jacobs R, Joannes-Boyau O, et al: Septic AKI in ICU patients. Diagnosis, pathophysiology, and treatment type, dosing, and timing: a comprehensive review of recent and future developments. Ann Intensive Care 2011;1:32.

63 Ronco C, Brendolan A, d'Intini V, Ricci Z, Wratten ML, Bellomo R: Coupled plasma filtration adsorption: rationale, technical development and early clinical experience. Blood Purif 2003;21:409-416.

64 Rimmelé T, Wey PF, Bernard N, et al: Hemofiltration with the Cascade system in an experimental porcine model of septic shock. Ther Apher Dial 2009;13:63-70.

-65 Busund R, Koukline V, Utrobin U, Nedashkovsky E: Plasmapheresis in severe sepsis and septic shock: a prospective, randomised, controlled trial. Intensive Care Med 2002;28: 1434-1439.

66 Carcillo JA, Kellum J: Is there a role for plasmapheresis/plasma exchange therapy in septic shock, MODS, and thrombocytopeniaassociated multiple organ failure? We still do not know - but perhaps we are closer. Intensive Care Med 2002;28:1373-1375.

-67 Rimmelé T, Assadi A, Cattenoz M, et al: High-volume haemofiltration with a new haemofiltration membrane having enhanced adsorption properties in septic pigs. Nephrol Dial Transplant 2009;24:421-427.

68 Davies B, Cohen J: Endotoxin removal devices for the treatment of sepsis and septic shock. Lancet Infect Dis 2011;11:65-71.

-69 Patel P, Bangalore VG, Cantwell WS, Troxclair S, Scott KL, Conrad S: Fulminant meningococcal sepsis: localized outbreak of three patients treated with therapeutic plasma exchange by membrane filtration. Blood Purif 2010;30:108-110. 